\title{
Fixed Point Theorem for Compatible Mapping in Fuzzy Metric Space
}

\author{
Raghu Nandan Patel ${ }^{1}$, Manoj Kumar Tiwari ${ }^{2}$ \\ ${ }^{1}$ Government Naveen College, Balrampur, Chhattisgarh, India \\ ${ }^{2}$ Government Girls Polytechnic College, Bilaspur, Chhattisgarh, India
}

\begin{abstract}
The present paper we establish a common fixed point theorem for compatible pair of self maps in a fuzzy metric space.
\end{abstract}
2000 Mathematics Subject Classification: 54H25, 47H10.

Key Words and phrases: Common fixed point, Fuzzy metric space, compatible maps.

\section{Introduction}

The concept of fuzzy sets was initiated by Zadeh [27] in 1965 and the concept of fuzzy metric space was introduced by Kramosil and Michalek [12]. Grabiec [7] proved the contraction principle in the setting of the fuzzy metric space which was further generalization of results by Subrahmanyam [25] for a pair of commuting mappings. Also, George and Veeramani [6] modified the notion of fuzzy metric spaces with the help of continuous t-norm, by generalizing the concept of probabilistic metric space to fuzzy situation. Also, Jungck and Rhoades [10] defined a pair of self mappings to be weakly compatible if they commute at their coincidence points. Balasubramaniam et.al. [1] proved a fixed point theorem, which generalizes a result of Pant for fuzzy mappings in fuzzy metric space. Jha et.al.[9] has proved a common fixed point theorem for four self mappings in fuzzy metric space under the weak contractive conditions. Also, B. Singh and S. Jain [23] introduced the notion of semi-compatible maps in fuzzy metric space and compared this notion with the notion of compatible map, compatible map of type $(\alpha)$, compatible map of type $(\beta)$ and obtained some fixed point theorems in complete fuzzy metric space in the sense of Grabiec [7]. As a generalization of fixed point results of Singh and Jain [23], Mishra et. al. [15] proved a fixed point theorems in complete fuzzy metric space by replacing continuity condition with reciprocally continuity maps.

The purpose of this paper is to obtain a common fixed point theorem for compatible pair of self mappings in fuzzy metric space.

We have used the following notions:

DEFINITION 1.1([27]) Let $X$ be any set. A fuzzy set $A$ in $\mathrm{X}$ is a function with domain $\mathrm{X}$ and values in $[0,1]$.

DEFINITION 1.2([6]) A binary operation * : $[0,1] \times[0,1]$ $\rightarrow[0,1]$ is called a continuous t-norm if, $([0,1], *)$ is an abelian topological monoid with unit 1 such that $\mathrm{a} * \mathrm{~b} \leq \mathrm{c}$ * d whenever

$\mathrm{a} \leq \mathrm{c}$ and $\mathrm{b} \leq \mathrm{d}$, for all $\mathrm{a}, \mathrm{b}, \mathrm{c}, \mathrm{d}$ in $[0,1]$.

For an example: $a * b=a b, a * b=\min \{a, b\}$.
DEFINITION 1.3([6]) The triplet $(\mathrm{X}, \mathrm{M}, *)$ is called a fuzzy metric space (shortly, a FM-space)

if, $\mathrm{X}$ is an arbitrary set, $*$ is a continuous t-norm and $\mathrm{M}$ is a fuzzy set on $\mathrm{X} \times \mathrm{X} \times[0,1)$ satisfying

the following conditions: for all $x, y, z$ in $\mathrm{X}$, and $\mathrm{s}, \mathrm{t}>0$,

(i) $\mathrm{M}(x, y, 0)=0, \mathrm{M}(x, y, \mathrm{t})>0$;

(ii) $\mathrm{M}(x, y, \mathrm{t})=1$ for all $\mathrm{t}>0$ if and only if $x=y$,

(iii) $\mathrm{M}(x, y, \mathrm{t})=\mathrm{M}(y, x, \mathrm{t})$,

(iv) $\mathrm{M}(x, y, \mathrm{t}) * \mathrm{M}(y, z, \mathrm{~s}) \leq \mathrm{M}(x, z, \mathrm{t}+\mathrm{s})$,

(v) $\mathrm{M}(x, y, \cdot):[0, \infty) \rightarrow[0,1]$ is left continuous.

In this case, $\mathrm{M}$ is called a fuzzy metric on $\mathrm{X}$ and the function $\mathrm{M}(x, y, \mathrm{t})$ denotes the degree of nearness between $x$ and $y$ with respect to $t$.

Also, we consider the following condition in the fuzzy metric space $(\mathrm{X}, \mathrm{M}, *)$ :

(vi) $\operatorname{limt} \rightarrow \infty \mathrm{M}(x, y, \mathrm{t})=1$, for all $x, y \in \mathrm{X}$.

It is important to note that every metric space $(\mathrm{X}, \mathrm{d})$ induces a fuzzy metric space $(X, M, *)$ where $a * b=\min \{a, b\}$ and for all $\mathrm{a}, \mathrm{b} \in \mathrm{X}$, we have $M(x, y, t)=\frac{t}{t+d(x, y)}$, for all $\mathrm{t}>0$, and $\mathrm{M}(x, y, 0)=0$, so-called the fuzzy metric space induced by the metric $\mathrm{d}$.

DEFINITION 1.4([6]) A sequence $\{x \mathrm{n}\}$ in a fuzzy metric space $(X, M, *)$ is called a Cauchy sequence if, limn $\rightarrow \infty$ $\mathrm{M}(x \mathrm{n}+\mathrm{p}, x \mathrm{n}, \mathrm{t})=1$ for every $\mathrm{t}>0$ and for each $\mathrm{p}>0$.

A fuzzy metric space $(\mathrm{X}, \mathrm{M}, *)$ is complete if, every Cauchy sequence in $\mathrm{X}$ converges in $\mathrm{X}$.

DEFINITION 1.5([6]) A sequence $\{x \mathrm{n}\}$ in a fuzzy metric space $(\mathrm{X}, \mathrm{M}, *)$ is said to be convergent to $x$ in $\mathrm{X}$ if, limn $\rightarrow \infty \mathrm{M}(x \mathrm{n}, x, \mathrm{t})=1$, for each $\mathrm{t}>0$.

It is noted that since $*$ is continuous, it follows from the condition (iv) of Definition (1.3.) that the limit of a sequence in a fuzzy metric space is unique.

DEFINITION 1.6([1]) Two self mappings A and B of a fuzzy metric space $(\mathrm{X}, \mathrm{M}, *)$ are said to be compatible if, $\operatorname{limn} \rightarrow \infty \mathrm{M}(\mathrm{AB} x \mathrm{n}, \mathrm{BAxn}, \mathrm{t})=1$ whenever $\{x \mathrm{n}\}$ is a 


\section{International Journal of Science and Research (IJSR)}

ISSN (Online): 2319-7064

Index Copernicus Value (2013): 6.14 | Impact Factor (2014): 5.611

sequence such that $\lim n \rightarrow \infty A x n=\lim n \rightarrow \infty B x n=p$, for some $\mathrm{p}$ in $\mathrm{X}$.

LEMMA 1.11([20]) Let (X, M, *) be a fuzzy metric space. If there exists $\mathrm{k} \in(0,1)$ such that $\mathrm{M}(x, y, \mathrm{kt}) \geq \mathrm{M}(x, y, \mathrm{t})$ then $x=y$.

PROPOSITION 1.12: Let $A$ and $B$ be compatible, self mappings of a fuzzy metric space $X$,

(1) If $A y=B y$ then $A B y=B a y$.

(2) If $A x n, B x n \rightarrow y$, for some $y$ is $X$ then

(a) BAxn $\rightarrow$ Ay if A is continuous.

(b) If $\mathrm{A}$ and $\mathrm{B}$ are continuous at $\mathrm{y}$ then $\mathrm{Ay}=\mathrm{By}$ and $\mathrm{ABy}=$ BAy.

PROOF: (1) Let $A y=B y$ and $\{x n\}$ be a sequence in $X$ such that $\mathrm{xn}=\mathrm{y}$ for all $\mathrm{n}$. Then Axn, Bxn $\rightarrow$ Ay. Now by the compatibility of $\mathrm{A}$ and $\mathrm{B}$, we have

$\mathrm{M}(\mathrm{ABy}, \mathrm{BAy}, \mathrm{t})=\mathrm{M}(\mathrm{AB} x \mathrm{n}, \mathrm{BAxn}, \mathrm{t})=1$ which yields $\mathrm{ABy}=\mathrm{BAy}$.

(2) If $\mathrm{A} x \mathrm{n}, \mathrm{B} x \mathrm{n} \rightarrow \mathrm{y}$, for some $\mathrm{y}$ is $\mathrm{X}$ then

(a) By the continuity of $\mathrm{A}, \mathrm{ABxn} \rightarrow \mathrm{Ay}$ and by compatibility of A, B

$\mathrm{M}(\mathrm{AB} x \mathrm{n}, \mathrm{BA} x \mathrm{n}, \mathrm{t})=1$ as $\mathrm{n} \rightarrow \infty$, which yields $\mathrm{BAxn} \rightarrow \mathrm{Ay}$.

(b) If $A$ and $B$ are continuous then from (a) we have BAxn $\rightarrow$ Ay. But by the continuity of B, BAxn $\rightarrow$ By. Thus by uniqueness of the limit $\mathrm{Ay}=\mathrm{By}$. Hence $\mathrm{ABy}=\mathrm{BAy}$ from (1).

\section{Main Results}

THEOREM 2.1. Let $(X, M, *)$ be a complete fuzzy metric space with additional condition (vi) and with $\mathrm{a} * \mathrm{a} \geq \mathrm{a}$ for all $\mathrm{a} \in[0,1]$. Let $\mathrm{A}, \mathrm{B}, \mathrm{S}$ and $\mathrm{T}$ be mappings from $\mathrm{X}$ into itself such that

(i) $\mathrm{A}(\mathrm{X}) \subseteq \mathrm{T}(\mathrm{X}), \mathrm{B}(\mathrm{X}) \subseteq \mathrm{S}(\mathrm{X})$

(ii) One of the A, B, S or T is continuous,

(iii) $(\mathrm{A}, \mathrm{S})$ and $(\mathrm{B}, \mathrm{T})$ are compatible pairs of mappings,

(iv) $\mathrm{M}(\mathrm{A} x, \mathrm{~B} y, \mathrm{t}) \geq \phi(\min \{\mathrm{M}(\mathrm{Sx}, \mathrm{Ty}, \mathrm{t}), \mathrm{M}(\mathrm{Ax}, \mathrm{Ty}, \alpha \mathrm{t})$, $\mathrm{M}(\mathrm{Sx}, \mathrm{By},(2-\alpha) \mathrm{t})\}$,$) for all x, y \in \mathrm{X}, \alpha \in(0,2)$ and $\mathrm{t}>0$. where $\phi:[0,1] \rightarrow[0,1]$ is a continuous function such that $\phi(\mathrm{t})>\mathrm{t}$ for some $0<\mathrm{t}<1$. Then $\mathrm{A}, \mathrm{B}, \mathrm{S}$ and $\mathrm{T}$ have a unique common fixed point in $\mathrm{X}$.

PROOF: Let $x 0 \in \mathrm{X}$ be an arbitrary point. Then, since $\mathrm{A}(\mathrm{X})$ $\subseteq \mathrm{T}(\mathrm{X}), \mathrm{B}(\mathrm{X}) \subseteq \mathrm{S}(\mathrm{X})$, there exists $x 1, x 2 \in \mathrm{X}$ such that $\mathrm{A} x 0$ $=\mathrm{T} x 1$ and $\mathrm{B} x 1=\mathrm{S} x 2$. Inductively, we construct the sequences $\{y \mathrm{n}\}$ and $\{x \mathrm{n}\}$ in $\mathrm{X}$ such that $y 2 \mathrm{n}=\mathrm{A} x 2 \mathrm{n}=$ $\mathrm{T} x 2 \mathrm{n}+1$ and $y 2 \mathrm{n}+1=\mathrm{B} x 2 \mathrm{n}+1=\mathrm{S} x 2 \mathrm{n}+2$, for $\mathrm{n}=0,1,2, \ldots$.

Now, we put $\alpha=1-\mathrm{q}$ with $\mathrm{q} \in(0,1)$ in (iv), we have

$\mathrm{M}(y 2 \mathrm{n}, y 2 \mathrm{n}+1, \mathrm{t})=\mathrm{M}(\mathrm{A} x 2 \mathrm{n}, \mathrm{B} x 2 \mathrm{n}+1, \mathrm{t})$

$\geq \phi(\min \{\mathrm{M}(\mathrm{S} x 2 \mathrm{n}, \mathrm{T} x 2 \mathrm{n}+1, \mathrm{t}), \mathrm{M}(\mathrm{A} x 2 \mathrm{n}, \mathrm{T} x 2 \mathrm{n}+1,(1-\mathrm{q}) \mathrm{t})$, $\mathrm{M}(\mathrm{S} x 2 \mathrm{n}, \mathrm{B} x 2 \mathrm{n}+1,(1+\mathrm{q}) \mathrm{t})\})$.

That is,

$\mathrm{M}(y 2 \mathrm{n}, y 2 \mathrm{n}+1, \mathrm{t}) \geq \phi(\min \{\mathrm{M}(y 2 \mathrm{n}-1, y 2 \mathrm{n}, \mathrm{t}), \mathrm{M}(y 2 \mathrm{n}, y 2 \mathrm{n}+1$, t), $\mathrm{M}(y 2 \mathrm{n}-1, y 2 \mathrm{n}+1,(1+\mathrm{q}) \mathrm{t})\})$

$\geq \phi(\min \{\mathrm{M}(y 2 \mathrm{n}-1, y 2 \mathrm{n}, \mathrm{t}), \mathrm{M}(y 2 \mathrm{n}, y 2 \mathrm{n}+1, \mathrm{t}), \mathrm{M}(y 2 \mathrm{n}-1, y 2 \mathrm{n}$, t), $\mathrm{M}(y 2 \mathrm{n}-1, y 2 \mathrm{n}+1, \mathrm{qt})\})$

$\geq \mathrm{M}(y 2 \mathrm{n}-1, y 2 \mathrm{n}, \mathrm{t}) * \mathrm{M}(y 2 \mathrm{n}, y 2 \mathrm{n}+1, \mathrm{t}) * \mathrm{M}(y 2 \mathrm{n}, y 2 \mathrm{n}+1, \mathrm{qt})$.

Since t-norm $*$ is continuous, letting $\mathrm{q} \rightarrow 1$, we have
$\mathrm{M}(y 2 \mathrm{n}, y 2 \mathrm{n}+1, \mathrm{t}) \geq \phi(\min \{\mathrm{M}(y 2 \mathrm{n}-1, y 2 \mathrm{n}, \mathrm{t}), \mathrm{M}(y 2 \mathrm{n}, y 2 \mathrm{n}+1$, t), $\mathrm{M}(y 2 \mathrm{n}, y 2 \mathrm{n}+1, \mathrm{t})\}$

$\geq \phi(\min \{\mathrm{M}(y 2 \mathrm{n}-1, y 2 \mathrm{n}, \mathrm{t}), \mathrm{M}(y 2 \mathrm{n}, y 2 \mathrm{n}+1, \mathrm{t})\})$.

It follows that, $\mathrm{M}(y 2 \mathrm{n}, y 2 \mathrm{n}+1, \mathrm{t})>\mathrm{M}(y 2 \mathrm{n}-1, y 2 \mathrm{n}, \mathrm{t})$, since $\phi$ (t) $>$ t for each $0<\mathrm{t}<1$.

Similarly, $\mathrm{M}(y 2 \mathrm{n}+1, y 2 \mathrm{n}+2, \mathrm{t})>\mathrm{M}(y 2 \mathrm{n}, \quad y 2 \mathrm{n}+1, \mathrm{t})$ Therefore, in general, we have

$\mathrm{M}(y \mathrm{n}, y \mathrm{n}+1, \mathrm{t}) \geq \phi\left(\mathrm{M}\left(y_{\mathrm{n}}-1, y \mathrm{n}, \mathrm{t}\right)\right)>\mathrm{M}\left(y_{\mathrm{n}}-1, y \mathrm{n}, \mathrm{t}\right)$.

Therefore, $\{\mathrm{M}(y \mathrm{n}, y \mathrm{n}+1, \mathrm{t})\}$ is an increasing sequence of positive real numbers in $[0,1]$ and tends to a limit, say $\lambda \leq 1$. We claim that $\lambda=1$. If $\lambda<1$, then $\mathrm{M}(y \mathrm{n}, y \mathrm{n}+1, \mathrm{t}) \geq \phi$ $(\mathrm{M}(y \mathrm{n}-1, y \mathrm{n}, \mathrm{t}))$.

So, on letting $\mathrm{n} \rightarrow \infty$, we get $\operatorname{limn} \rightarrow \infty \mathrm{M}(y \mathrm{n}, y \mathrm{n}+1, \mathrm{t}) \geq$ $\phi(\operatorname{limn} \rightarrow \infty \mathrm{M}(y \mathrm{n}, y \mathrm{n}+1, \mathrm{t}))$

that is, $\lambda \geq \mathrm{r}(\lambda)>\lambda$, a contradiction. Thus, we have $\lambda=1$.

Now, for any positive integer $\mathrm{p}$, we have

$\mathrm{M}(y \mathrm{n}, y \mathrm{n}+\mathrm{p}, \mathrm{t}) \geq \mathrm{M}(y \mathrm{n}, y \mathrm{n}+1, \mathrm{t}) * \mathrm{M}(y \mathrm{n}+1, y \mathrm{n}+2, \mathrm{t} / \mathrm{p}) * \ldots$ $* \mathrm{M}(y \mathrm{n}+\mathrm{p}-1, y \mathrm{n}+\mathrm{p}, \mathrm{t} / \mathrm{p})$.

Letting $\mathrm{n} \rightarrow \infty$, we get $\operatorname{limn} \rightarrow \infty \mathrm{M}(y \mathrm{n}, y \mathrm{n}+\mathrm{p}, \mathrm{t}) \geq 1 * 1 * \ldots$ $* 1=1$.

Thus, we have limn $\rightarrow \infty \mathrm{M}(y \mathrm{n}, y \mathrm{n}+\mathrm{p}, \mathrm{t})=1$. Hence, $\{y \mathrm{n}\}$ is a Cauchy sequence in $X$. Since $X$ is complete metric space, so the sequence $\{y n\}$ converges to a point $u$ (say) in $X$ and consequently, the subsequences $\{\mathrm{A} x 2 \mathrm{n}\},\{\mathrm{S} x 2 \mathrm{n}\},\{\mathrm{T} x 2 \mathrm{n}+1\}$ and $\{\mathrm{B} x 2 \mathrm{n}+1\}$ also converges to $\mathrm{u}$.

We first consider the case when $(\mathrm{A}, \mathrm{S})$ and $(\mathrm{B}, \mathrm{T})$ are compatible maps. Since A and S are compatible maps, so we have limn $\rightarrow \infty \mathrm{M}(\mathrm{AS} x \mathrm{n}, \mathrm{SA} x \mathrm{n}, \mathrm{t})=1$ whenever $\{x \mathrm{n}\}$ is a sequence such that $\lim n \rightarrow \infty A x n=\lim n \rightarrow \infty S x n=u$, for some $\mathrm{u}$ in $\mathrm{X}$. Therefore, we get $\mathrm{Au}=\mathrm{Su}$. And also B and $\mathrm{T}$ are compatible maps, so we have $\operatorname{limn} \rightarrow \infty \mathrm{M}(\mathrm{BT} x \mathrm{n}, \mathrm{TB} x \mathrm{n}$, t) $=1$ whenever $\{x \mathrm{n}\}$ is a sequence such that $\lim \mathrm{n} \rightarrow \infty \mathrm{B} x \mathrm{n}$ $=\lim \mathrm{n} \rightarrow \infty \mathrm{T} x \mathrm{n}=\mathrm{u}$, for some $\mathrm{u}$ in $\mathrm{X}$.

We claim that $A u=u$. For this, suppose that $A u \neq u$.

Then, setting $x=\mathrm{u}$ and $\mathrm{y}=x 2 \mathrm{n}+1$ in contractive condition (iv) with $\alpha=1$, we get

$\mathrm{M}(\mathrm{Au}, \mathrm{B} x 2 \mathrm{n}+1, \mathrm{t}) \geq \phi(\min \{\mathrm{M}(\mathrm{Su}, \mathrm{T} x 2 \mathrm{n}+1, \mathrm{t}), \mathrm{M}(\mathrm{Au}$, $\mathrm{T} x 2 \mathrm{n}+1, \mathrm{t}), \mathrm{M}(\mathrm{Su}, \mathrm{B} x 2 \mathrm{n}+1, \mathrm{t})\})$.

Letting $\mathrm{n} \rightarrow \infty$, we get $\mathrm{M}(\mathrm{Au}, \mathrm{u}, \mathrm{t}) \geq \mathrm{r}(\mathrm{M}(\mathrm{Au}, \mathrm{u}, \mathrm{t}))>\mathrm{M}(\mathrm{Au}$, $\mathrm{u}, \mathrm{t})$, which implies that $\mathrm{u}=\mathrm{Au}$.

Thus, we have $u=A u=$ Su. Since $A(X) \subseteq T(X)$, so there exists $\mathrm{v}$ in $\mathrm{X}$ such that $\mathrm{u}=\mathrm{Au}=\mathrm{Tv}$.

Therefore, setting $x=x 2 \mathrm{n}$ and $\mathrm{y}=\mathrm{v}$ in contractive condition (iv) with $\alpha=1$, we get

$\mathrm{M}(\mathrm{A} x 2 \mathrm{n}, \mathrm{Bv}, \mathrm{t}) \geq \phi(\min \{\mathrm{M}(\mathrm{S} x 2 \mathrm{n}, \mathrm{Tv}, \mathrm{t}), \mathrm{M}(\mathrm{A} x 2 \mathrm{n}, \mathrm{Tv}, \mathrm{t})$, $\mathrm{M}(\mathrm{S} x 2 \mathrm{n}, \mathrm{Bv}, \mathrm{t})\})$.

Letting $\mathrm{n} \rightarrow \infty$, we get $\mathrm{M}(\mathrm{Au}, \mathrm{Bv}, \mathrm{t}) \geq \phi(\mathrm{M}(\mathrm{Au}, \mathrm{Bv}, \mathrm{t}))>$ $\mathrm{M}(\mathrm{Au}, \mathrm{Bv}, \mathrm{t})$, which implies that $\mathrm{u}=\mathrm{Bv}$.

Thus, we have $u=B v=T v$. Therefore, we get $u=A u=S u$ $=\mathrm{Bv}=\mathrm{Tv}$.

Now, since $u=B v=T v$, so by the compatibility of $(B, T)$, it follows that $\mathrm{BTv}=\mathrm{TBv}$ and so we get $\mathrm{Bu}=\mathrm{BTv}=\mathrm{TBv}=$ $\mathrm{Tu}$. Thus, from the contractive condition (iv) with $\alpha=1$, we have

$\mathrm{M}(\mathrm{Au}, \mathrm{Bu}, \mathrm{t}) \geq \phi(\min \{\mathrm{M}(\mathrm{Su}, \mathrm{Tu}, \mathrm{t}), \mathrm{M}(\mathrm{Au}, \mathrm{Tu}, \mathrm{t})$, $\mathrm{M}(\mathrm{Su}, \mathrm{Bu}, \mathrm{t})\})$, that is, $\mathrm{M}(\mathrm{u}, \mathrm{Bu}, \mathrm{t})>\mathrm{M}(\mathrm{u}, \mathrm{Bu}, \mathrm{t})$, which is a contradiction. This implies that $\mathrm{u}=\mathrm{Bu}$. Similarly, using 


\section{International Journal of Science and Research (IJSR) \\ ISSN (Online): 2319-7064}

Index Copernicus Value (2013): 6.14 | Impact Factor (2014): 5.611

condition (iv) with $\alpha=1$, one can show that $A u=u$. Therefore, we have $\mathrm{u}=\mathrm{Au}=\mathrm{Bu}=\mathrm{Tu}=\mathrm{Su}$. Hence, the point $\mathrm{u}$ is a common fixed point of $\mathrm{A}, \mathrm{B}, \mathrm{S}$ and $\mathrm{T}$.

\section{Uniqueness}

The uniqueness of a common fixed point of the mappings A, $\mathrm{B}, \mathrm{S}$ and $\mathrm{T}$ be easily verified by using (iv). In fact, if $\mathrm{u} 0$ be another fixed point for mappings A, B, S and T. Then, for $\alpha$ $=1$, we have

$\mathrm{M}(\mathrm{u}, \mathrm{u} 0, \mathrm{t})=\mathrm{M}(\mathrm{Au}, \mathrm{Bu} 0, \mathrm{t}) \geq \phi(\min \{\mathrm{M}(\mathrm{Su}, \mathrm{Tu} 0, \mathrm{t}), \mathrm{M}(\mathrm{Au}$, $\mathrm{Tu} 0, \mathrm{t}), \mathrm{M}(\mathrm{Su}, \mathrm{Bu} 0, \mathrm{t})\})$,

$\geq \phi(\mathrm{M}(\mathrm{u}, \mathrm{u} 0, \mathrm{t}))>\mathrm{M}(\mathrm{u}, \mathrm{u} 0, \mathrm{t})$, and hence, we get $\mathrm{u}=\mathrm{u} 0$.

This completes the proof of the theorem.

\section{References}

[1] Balasubramaniam P, Muralishankar S \& Pant R P, Common fixed points of four mappings in a fuzzy metric space, J. Fuzzy Math., 10(2)(2002), 379.

[2] Cho Y J, Fixed point in fuzzy metric space, J. Fuzzy Math., 5(1997), 940.

[3] Cho Y J, Pathak H K, Kang S M \& Jung J S, Common fixed points of compatible mappings of type (B) on on fuzzy metric space, Fuzzy Sets and Systems, 93(1998), 99.

[4] Chauhan M S, Badshah V M, \& Chouhan V S, Common fixed point of semi-compatible maps in fuzzy metric space, Kath. Univ. J. Sci. Engg. Tech., $6(1)(2010), 70$.

[5] Chugh R \& Kumar K, Common fixed point theorem in fuzzy metric spaces, Bull. Cal. Math. Soc., 94(1)(2002), 17.

[6] George A \& Veeramani P, On some results in fuzzy metric space, Fuzzy Sets and Systems, 64(1994), 395.

[7] Grabiec G, Fixed points in fuzzy metric spaces, Fuzzy Sets and Systems, 27(1988), 385.

[8] Jha K, Generalized common fixed point theorem in fuzzy metric space, The Nepali Math. Sci. Report, 29(12)(2009), 69.

[9] Jha K, Karadzhov G E \& Pecaric J, A generalized common fixed point in fuzzy metric space, The Nepali Math. Sci. Report, 30(1-2)(2010), 62.

[10] Jungck G \& Rhoades B E, Fixed point for set valued functions without continuity, Indian J. Pure Appl. Math., 29(3)(1998), 227.

[11] Khan M S, Pathak H K \& George R, Compatible compatible mappings of Type $(\mathrm{A}-1)$ and Type $\mathrm{A}-2$ and common fixed points in fuzzy metric spaces, Int. Math. Forum, 2(2007), 515.

[12] Kramosil O \& Michalek J, Fuzzy metric and statistical metric spaces, Kybernetika, 11(1975), 326.

[13] Kutukcu S, Sharma S \& Tokgoz H, A fixed point theorem in fuzzy metric spaces, Int. J. Math. Anal., 1(18)(2007), 861.

[14] Mishra S N, Common fixed points of compatible maps in FM- space, Math. Japon, 36(1991), 283.

[15] Mishra U, Ranadive A S and Gopal D, Some fixed points theorems in fuzzy metric space, Tamkang J. Math., 39(4)(2008), 309.

[16] Pant R P, Common fixed points of four mappings, Bull. Cal. Math. Soc., 90(1998), 281. [17] Pant R P \& Jha K,
A remark on common fixed points of four mappings in a fuzzy metric space, J. Fuzzy Math., 12(2)(2004), 433.

[17] Pant V, Discontinuity and fixed points in fuzzy metric space, J. Fuzzy Math.,16(1)(2008), 43.

[18] Rhoades B E, Contractive definitions and continuity, Contemporary Math., 72(1988), 233.

[19] Sharma S, Common fixed point theorems in fuzzy metric spaces, Fuzzy Sets and Systems, 127(2002), 345.

[20] Sharma S, Pathak A \& Tiwari R, Common fixed point of weakly compatible maps without continuity in fuzzy metric space, Int. J. Appl. Math., 20(4)(2007), 495.

[21] Singh B \& Chauhan M S, Common fixed point of compatible maps in fuzzy metric space, Fuzzy sets and Systems, 115(2000), 471.

[22] Singh B \& Jain S, Semi-compatible and fixed point theorems in fuzzy metric space, Chungcheong Math. Soc., 18(2005), 1.

[23] Singh S L \& Tomor A, Weaker forms of commuting mappings and existence of fixed points, J. Korean Soc. Math. Edu. Ser B: Pure Appl. Math., 10(3)(2003), 145.

[24] Subrahmanyam P V, A common fixed point theorem in fuzzy metric space, Inform. Sci., 83(1995), 103.

[25] Vasuki R, Common fixed points for R-weakly commuting mappings in fuzzy metric spaces, Indian J. Pure and Appl. Math., 30(1999), 419.

[26]Zadeh L A, Fuzzy sets, Inform. and Control., 89(1965), 338.

\section{Author Profile}

Raghu Nandan Patel is in Department of Mathematics, Government Naveen College, Balrampur, Chhattisgarh, India

Manoj Kumar Tiwari is in Department of Mathematics, Government Girls Polytechnic College, Bilaspur, Chhattisgarh, India 